\title{
Infection efficiency of Phaeoisariopsis personata and the influence of different wetness patterns on germ-tube growth of the pathogen
}

\author{
K. D. R. WADIA and D. R. BUTLER \\ Resource Management Program. International Crops Research Institute for the Semi-Arid Tropics \\ (ICRISAT), Patancheru P.O., Andhra Pradesh 502 324, India
}

Controlled environment studies with Phaeoisariopsis personata, the causal agent of late leaf spot disease of groundnut (Arachis hypogaea), have shown that infection is enhanced if leaves are exposed to alternate wet and dry periods (intermittent wetness) compared with continuous wetness. Detailed investigations to elucidate this phenomenon revealed more germ tubes per conidium and more branching of germ tubes with intermittent wetness than with continuous wetness. With intermittent wetness there was clear evidence of tropic growth of germ tubes and branches towards stomata and subsequent penetration. With continuous wetness, germ tube growth did not appear to be directional and germ tubes commonly passed over the stomatal guard cells, therefore leading to relatively few stomatal penetrations. For both wetness regimes, stomatal penetrations continued to increase with increased leaf wetness for at least 6 days after inoculation and there was a linear relationship between the number of stomatal penetrations and the number of resultant lesions. Infection efficiency was markedly increased when the spore load was reduced to 0.1 conidia per $\mathrm{cm}^{2}$ (about one spore per leaflet).

\section{INTRODUCTION}

The infection process (spore germination, germtube growth and host penetration; Gäumann, 1950 ) is critical for the establishment of contact with host cells prior to colonization. Many foliar disease fungi require the presence of free water on the leaf surface for infection to occur and the required duration of leaf wetness varies for different fungi. Long periods of leaf wetness (greater than 1 day) are uncommon in nature and slow-growing fungi must be able to withstand alternate wet and dry periods (intermittent wetness) during infection. For these fungi, the infection process could take several days depending on leaf wetness availability. The spores of some species (e.g. Botrytis cinerea, Cercospora musae and Monilinia fructicola) have the ability to tolerate severe drying and rehydrate rapidly to full turgor when wetness becomes available (Good \& Zathureczky, 1967). Although numerous fungi can withstand drying, their reaction to interruptions in leaf wetness varies. Compared with continuous leaf wetness, infection with interrupted wetness may be reduced (c.g. Septoria tritici on wheat; Shaw, 1991), may remain the same (c.g. Stemphyllium botryosum f. sp lycopersici on tomato; Bashi \& Rotem, 1974) or may be increased (e.g. Cercospora carotae on carrot; Carisse \& Kushalappa, 1992).

Late leaf spot disease of groundnut (Arachis hypogaea) caused by Phaeiosariopsis personata occurs in the majority of groundnut-growing regions of the world and, in the semi-arid tropics, epidemics of the disease are very common in the rainy season. Long periods of leaf wetness are associated with severe disease (Shew et al., 1988) and increased infection has been demonstrated with alternate high and low relative humidity (r.h.) compared with continuously high r.h. (Lannou \& Blizoua Bi, 1989). Similarly, Butler et al. (1994) reported enhanced infection with leaves exposed to intermittent wetness compared with continuous wetness. Shew et al. (1988) pointed out that long periods of uninterrupted leaf wetness rarely occur in the field and spontaneous infection by $\boldsymbol{P}$. personata must often develop during discontinuous periods of high r.h. Abdou et al. (1974) and Lannou and Blizoua Bi (1989) indicated that the infection process of $P$. personata takes longer than 6-8 days, and Butler (1990) suggested that the infection process stops when the leaves are dry and restarts when leaves are re-wetted. This view 
has particular epidemiological significance in semi-arid climates where leaves frequently remained wet for just a few hours at a time, even in the monsoon season.

Infection efficiency (IE) has been defined as the ratio between lesion density and spore density (Schein, 1964) but we are adopting a slightly modified definition:

$$
I E=\frac{L D_{\mathrm{c}}}{C D}
$$

where $L D_{\mathrm{c}}$ is the observed lesion density corrected for multiple infections (Gregory, 1948 ) and $C D$ is the density of conidia on the leaf surface (number per unit area).

The objective of the present study was to elucidate mechanisms by which infection efficiency increases with $P$. personata on groundnut when leaf wetness is interrupted and to examine the effect of spore load on infection efficiency.

\section{MATERIALS AND METHODS}

\section{Plant material}

Experiments were carried out on the groundnut cultivar TMV 2, susceptible to late leaf spot disease. Plants were raised in a glasshouse in $13-\mathrm{cm}$ diameter plastic pots. Four seeds were sown in each pot containing a potting medium of $50 \%$ loam, $25 \%$ sand and $25 \%$ compost. The medium was sterilized and no root nodulation was observed. Seedlings were later thinned to two healthy plants per pot and fed once a week with Broughton's nutrient solution (Broughton \& Dilworth, 1971). Healthy plants were maintained without the use of pesticides and insect damage was eliminated by removing affected plants. Four-week-old plants were used in our experiments.

Coolers were operated in the glasshouse to prevent the air temperature exceeding $35^{\circ} \mathrm{C}$ but the minimum temperature and humidity depended largely on external ambient conditions. The minimum temperature varied between 12 and $20^{\circ} \mathrm{C}$, and the r.h. ranged from 30 to $50 \%$ during the day and from 60 to $90 \%$ at night. The average irradiance in the glasshouse was about $60 \%$ of daylight.

\section{Inoculation}

Inoculum of $\boldsymbol{P}$. personata was multiplied on groundnut leaves using isolates derived from locally collected conidia as described by Wadia
\& Butler (1994). The inoculum was harvested with a cyclone spore collector and stored at $4^{\circ} \mathrm{C}$.

On each plant the third and fourth leaves from the top (four leaves per pot) were tagged prior to inoculation. Immediately before inoculation, a suspension of conidia in about $200 \mathrm{ml}$ distilled water with a few drops of wetting agent (Tween 80), was prepared. The spore concentration was determined with a haemocytometer and adjusted to give approximately 10000 spores $/ \mathrm{ml}$. The suspension was sprayed with an atomiser, ensuring that both sides of the tagged leaves were completely wetted. Water retention, assessed by weighing 25 leaves before and after spraying with the atomiser, was $0.006 \pm 0.0002 \mathrm{mg} / \mathrm{cm}^{2}$ so we estimate that about 60 conidia $/ \mathrm{cm}^{2}$ (the sum of adaxial and abaxial leaf surfaces) were deposited.

\section{Controlled environment}

Immediately after inoculation, plants were placed in dew chambers at $23^{\circ} \mathrm{C}$ (Butler et al., 1994) to ensure the presence of liquid water on the leaves for the required periods. After removing plants from the dew chamber, leaves were dried in front of a fan before transferring the plants to a controlled environment cabinet for dry periods within the experimental treatment, or to wait for symptom development after the end of the treatment.

\section{Lesion density assessment}

Plants were inspected and the number of lesions on inoculated leaves were counted daily. Incipient lesions (necrotic specks) were counted as soon as they were detected and where more than one lesion coalesced during growth, a single count was recorded. After the number of lesions had ceased increasing (14-16 days after inoculation), inoculated leaves were removed and the leaf area determined with a leaf area meter (Model 3100, LI-COR, Nebraska, USA). Usually coalescence caused the number of lesions to decrease at the end of the counting period, but the maximum number of lesions prior to this was used to calculate observed lesion density. Corrected lesion density was obtained by transforming the observed lesion density to allow for multiple infections (Gregory, 1948). assuming 20 infection sites $/ \mathrm{cm}^{2}$ leaf area. This assumption was based on observations of leaf samples from the field, collected at times when 
late leaf spot disease was most severe. The maximum lesion density across several seasons was nearly 20 per $\mathrm{cm}^{2}$ leaf area. Details of the corrections at several lesion densities are shown in Table 1.

\section{Experiments}

\section{Continuous wetness versus intermittent wetness (potted plants)}

Continuous leaf wetness was compared with intermittent leaf wetness by providing total wetness periods from $16-128 \mathrm{~h}$ and, for the intermittent treatment, there was $8 \mathrm{~h}$ of dryness in each $24 \mathrm{~h}$ period (see Table 2 for details). Dry periods were achieved by moving the pots to a plant growth cabinet (CG1011 Conviron, Winnipeg, Canada) set to $23^{\circ} \mathrm{C}, 80 \% R H$ and an irradiance of $59 \mathrm{~W} / \mathrm{m}^{2}$. In the continuous wetness treatment, dew chamber lights, which gave $54 \mathrm{~W} /$ $\mathrm{m}^{2}$, were operated during the same periods. Three pots (12 inoculated leaves) in each treatment were allocated for lesion counts and one pot (four inoculated leaves) were allocated for leaf clearing and microscopic observation. The experiment was repeated three times and, as similar results were always obtained, the data were pooled to calculate means and standard errors for each treatment separately.

For microscopic observations, inoculated leaflets were excised after leaf wetness periods of $16,24,32,40,48,64,88$ and $128 \mathrm{~h}$. One or two leaves were stained with Fungifluor stain, solution A (Polysciences Inc., Warrington, USA) without clearing and observed using a fluorescence microscope, but the remaining leaves were soaked in acetic acid and alcohol

Table 1. Lesion densities before and after correction for multiple infections (Gregory, 1948). The corrections assume 20 infection sites $/ \mathrm{cm}^{2}$ leaf area $(\mathrm{N})$, using the equation. $L D_{\mathrm{c}}=10 \mathrm{~N} \log _{\mathrm{e}}\left(\log _{10} \mathrm{~N}-\log _{10}(\mathrm{~N}-L D)\right)$, where $L D$ is the observed lesion density

\begin{tabular}{lc}
$L D$ & $L D_{\mathrm{c}}$ \\
\hline 0.10 & 0.10 \\
1.00 & 1.03 \\
2.00 & 2.11 \\
4.00 & 4.46 \\
6.00 & 7.13 \\
10.00 & 13.86 \\
\hline
\end{tabular}

(3:1) for $24 \mathrm{~h}$ to clear the chlorophyll. The solution was then drained and the leaflets were gently washed twice in distilled water and immersed in lactophenol cotton blue for $1 \mathrm{~h}$. Each leaflet was cut into two halves, the midrib was removed and each half was mounted in glycerine on a microscope slide. Initially, both adaxial and abaxial leaf surfaces were observed and no differences in germination, germ-tube production or stomatal penetration were found, but as stomata were clearer on the abaxial surface this was used for all subsequent observations. Four replicate areas, each of $2 \mathrm{~cm}^{2}$ from each treatment were examined with $\times 66$ magnification to assess percentage conidial germination, number of germ tubes and germ-tube branches, and the number of stomatal penetrations by germ tubes and germ-tube branches.

\section{Effect of spore concentration on infection}

Aqueous suspensions with 50000 and 10000 conidia/ml were prepared using a haemocytometer. Serial dilutions in sterile distilled water were made from the latter as stock solution to obtain spore concentrations of approximately $19,39,78,156,312,625,2500$, 10000 and 50000 spores $/ \mathrm{ml}$. Tagged leaves were inoculated with these suspensions as described above with similar retention and plants were subjected to 5 days of intermittent wetness ( $16 \mathrm{~h}$ wet and $8 \mathrm{~h}$ dry). Six pots (24 inoculated leaves) were allocated to each treatment and the experiment was conducted twice. Results from repeated experiments were similar therefore both sets of data were pooled.

\section{Influence of dry' periods on germ-tube number (in vitro)}

A single experiment was carried out to determine the influence of dry periods on the number of germ tubes per conidium. Two drops of a conidial suspension $(50000 / \mathrm{ml})$ were placed on cavity slides and conidia were incubated in the dark at $100 \%$ r.h. by placing the slides in petri dishes lined with moistened filter paper at $23 . \mathrm{C}$ for $24 \mathrm{~h}$. To obtain dry periods the slides were first allowed to dry in the laboratory and then placed into desiccators at about $25^{\circ} \mathrm{C}$ containing saturated $\mathrm{NaCl}$ to maintain the r.h. at $75 \%$ for $24 \mathrm{~h}$. Three wet/dry cycles were completed and 25 conidia were observed $u$ ith $\times 66$ magnitication at the end of each wet period. 
Table 2. Patterns of alternate wet and dry periods (h) for intermittent leaf wetness treatments. These were compared with continuous leaf wetness treatments for the same total periods

\begin{tabular}{|c|c|c|c|c|c|c|c|c|c|c|c|c|c|c|c|}
\hline \multirow{2}{*}{$\begin{array}{l}\text { Total wetness } \\
\text { period }(\mathrm{h})\end{array}$} & \multicolumn{15}{|c|}{ Wet/dry sequence $(\mathrm{h})$} \\
\hline & wet & dry & wet & dry & wet & dry & wet & dry & wet & dry & wet & dry & wet & dry & wet \\
\hline 16 & 16 & - & - & - & & - & - & - & - & & & & - & - & - \\
\hline 24 & 16 & 8 & 8 & - & - & - & - & - & & & - & - & & - & - \\
\hline 32 & 16 & 8 & 16 & - & - & - & & - & - & & - & & & - & \\
\hline 40 & 16 & 8 & 16 & 8 & 8 & - & & - & & & - & & & & \\
\hline 48 & 16 & 8 & 16 & 8 & 16 & - & - & - & & - & - & - & & & \\
\hline 64 & 16 & 8 & 16 & 8 & 16 & 8 & 16 & - & & - & - & - & & - & \\
\hline 88 & 16 & 8 & 16 & 8 & 16 & 8 & 16 & 8 & 16 & 8 & 8 & & & - & \\
\hline 128 & 16 & 8 & 16 & 8 & 16 & 8 & 16 & 8 & 16 & 8 & 16 & 8 & 16 & 8 & 16 \\
\hline
\end{tabular}

\section{RESULTS}

\section{Continuous wetness versus intermittent wetness} (potted plants)

\section{Lesion number}

The number of lesions resulting from inoculations increased with the total period of leaf wetness with both continuous and intermittent treatments, but two to three times as many lesions formed with intermittent wetness (Fig. 1a), confirming increased infection efficiency (Fig. 1b) with interrupted leaf wetness.

\section{Conidial germination}

After $16 \mathrm{~h}$ of wetness, $55-60 \%$ of conidia had germinated and by $24 \mathrm{~h}$ this had increased to $80-$ $85 \%$, but there was no significant increase subsequently. The germination percentage was similar in both continuous and intermittent wetness treatments.

\section{Germ-tube numbers}

$A$ rapid increase in the number of germ tubes growing directly from conidia was observed during the first $40 \mathrm{~h}$ of leaf wetness in both continuous and intermittent treatments (Fig. 2a), and there were significantly $(P<0.0001)$ more germ tubes with intermittent wetness. There was no further increase beyond $40 \mathrm{~h}$ with either treatment.

\section{Germ-tube branches}

The number of germ-tube branches continued to increase with increasing intermittent leaf wetness up to $88 \mathrm{~h}$, and there was a large difference in the number of branches between intermittent and continuous wetness (Fig. 2b). With continuous wetness, the number of germ-tube branches stopped increasing after $32 \mathrm{~h}$.

\section{Stomatal penetrations}

With intermittent wetness, stomatal penetrations increased linearly with the wetness period (Fig. 2c) and the pattern was similar to the number of germ-tube branches (Fig. 2b). Observations revealed clear tropism of germ tubes towards stomata with intermittent wetness (Fig. 3a), especially for germ-tube branches, resulting in frequent penetrations of the stomatal aperture. In continuous wetness treatments, there were far fewer penetrations which were predominantly by germ tubes (not branches) and they sometimes passed over stomatal guard cells and continued to grow without penetrating (Fig. 3b). Appresorium-like structures were commonly present at the point of stomatal entry in intermittent wetness, but similar structures were not seen with continuous wetness.

\section{Stomatal penetrations and lesion number}

The lesion number was linearly related to the number of stomatal penetrations. With continuous wetness (Fig. 4), stomatal penetrations did not exceed $25 / \mathrm{cm}^{2}$ even with a wetness period of $128 \mathrm{~h}$. In contrast, with intermittent wetness. there were more than three times the number of stomatal penetrations with a proportionate 

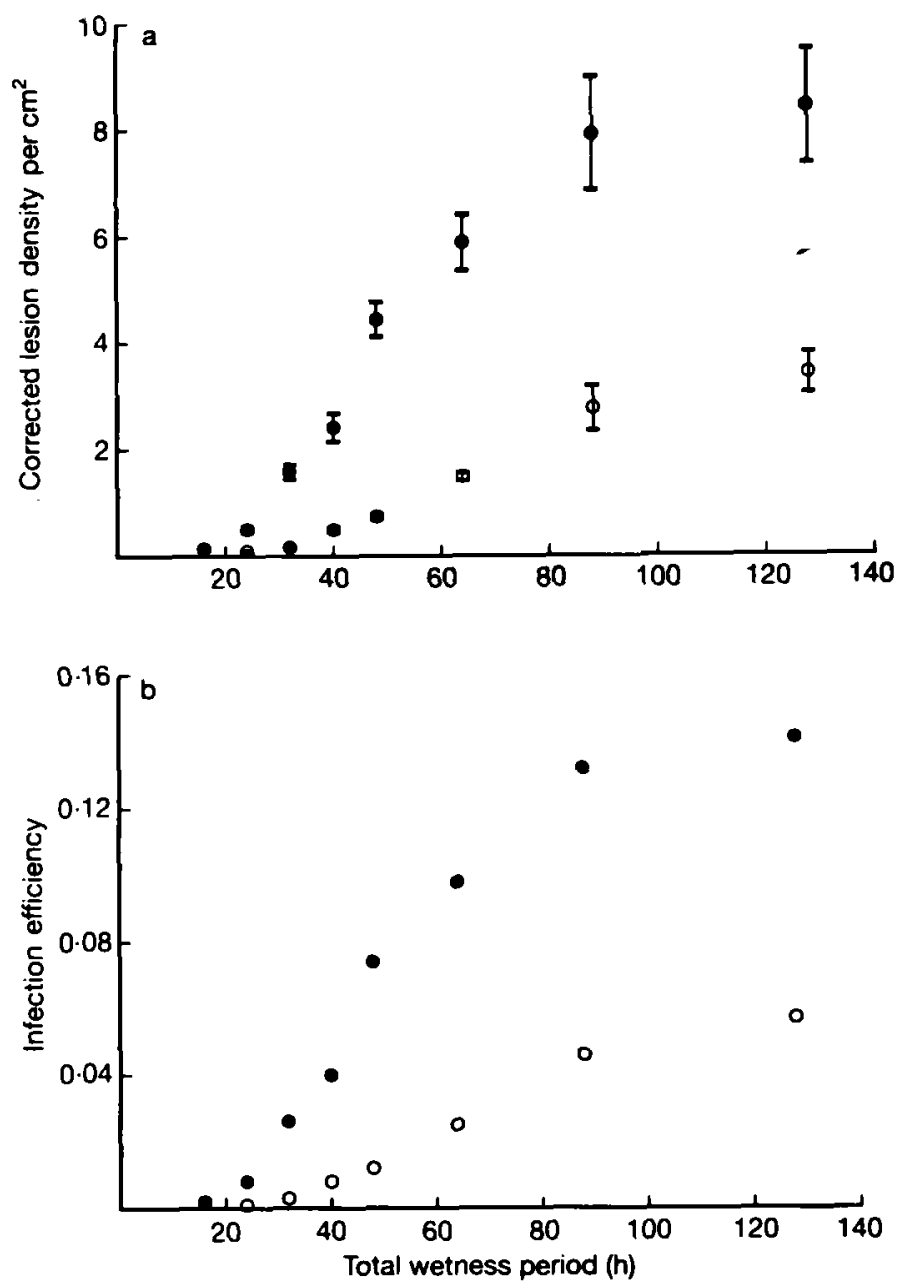

Fig. 1. The effects of intermittent ( $\bullet$ ) and continuous $(O)$ leaf wetness periods on (a) corrected lesion density and (b) infection efficiency after inoculating groundnut leaves with Phaeoisariopsis personata. Inoculum was applied as a suspension to give about 60 conidia/ $\mathrm{cm}^{2}$ (sum of both leaf surfaces) and lesions were counted daily until the number per unit leaf area reached a maximum. Vertical bars indicate standard errors.

increase in lesion number. The regression line in Fig. 4 is given by the equation:

$y=0.0767 \pm 0.004 x-0.254 \pm 0.125\left(r^{2}=0.90\right)$, where $y$ is corrected lesion density $\left(\right.$ per $\left.\mathrm{cm}^{2}\right)$ and $x$ is number of stomatal penetrations per $\mathrm{cm}^{2}$ leaf area. If a zero intercept is assumed, approximately 15 stomatal penetrations are required for each corrected lesion.

\section{Effect of spore concentration on infection}

With 300 conidia $/ \mathrm{cm}^{2}$ ( 50000 conidia $/ \mathrm{ml}$ ), 33 conidia gave rise to one lesion (corrected). whereas one lesion resulted from 13 conidia with 60 conidia $/ \mathrm{cm}^{2}$ ( 10000 conidia $\mathrm{ml}$ ) (Fig. 5), so the efficiency increased 2.5 times even after accounting for multiple infections. Further reduction in inoculum density greatly increased the infection efficiency and in the extreme case of 0.1 conidia $/ \mathrm{cm}^{2}$ ( 19 conidia $/ \mathrm{ml}$ ), which corresponds to about one conidium per leaflet, at least one lesion per leaf (four leaflets) developed on $50 \%$ of the inoculated leaves.

\section{Influence of dry periods on germ-tube number} (in vitro)

The average number of germ tubes on germinated conidia was $2.6 \pm 0.2$ anter $24 \mathrm{~h}$ of wetness and, 


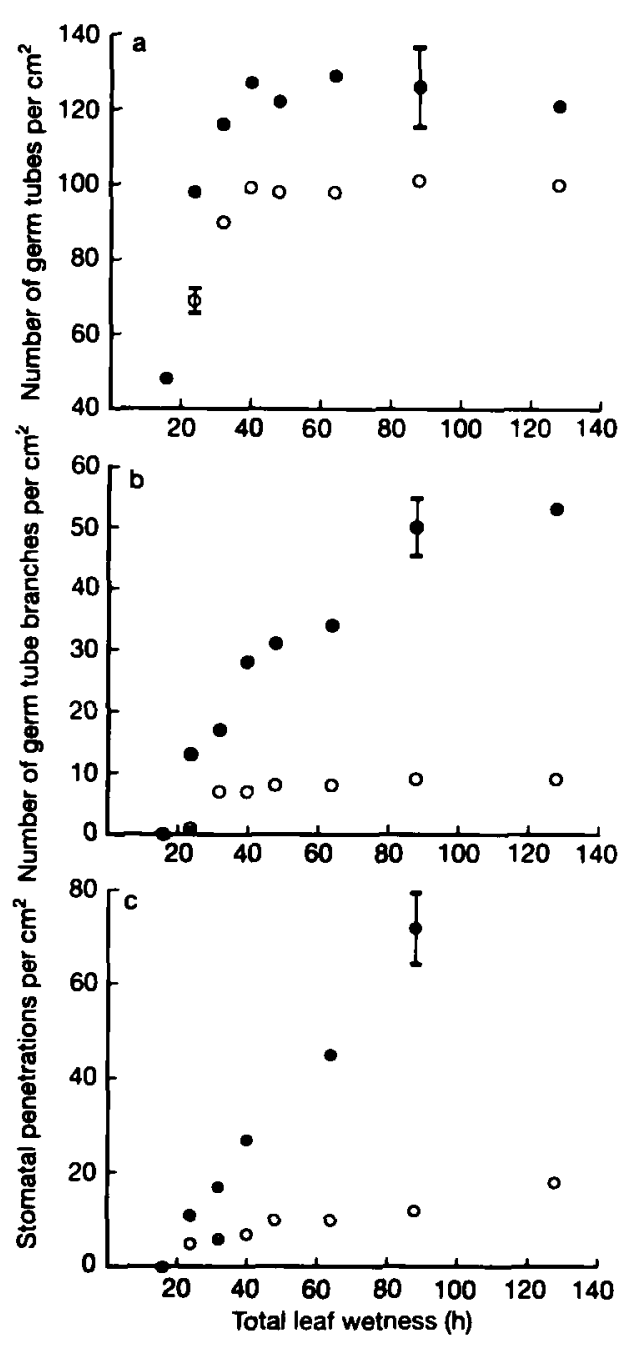

Fig. 2. Numbers of (a) germ tubes, (b) germ-tube branches and (c) stomatal penetrations by germ tubes and germ-tube branches for Phaeoisariopsis personata on the surface of groundnut leaves after different periods of leaf wetness. The inoculum density was about 60 conidia $/ \mathrm{cm}^{2}$ (sum of both leaf surfaces). intermittent wetness; $O$, continuous wetness. Vertical bars indicate minimum and maximum standard errors.

with continuous wetness up to $72 \mathrm{~h}$, there was no further increase. With wet/dry cycles the number of germ tubes per conidium continued to increase to 8.5 at the end of three cycles (Table 3). There were few germ-tube branches and they appeared only after the completion of two wet/dry cycles.

\section{DISCUSSION}

Conidial germination reached $80-85 \%$ in both continuous and intermittent wetness treatments, indicating that reduced germination was not responsible for reduced lesion number in continuous wetness. Abdou et al. (1974) observed that conidia of $P$. personata began to germinate 6$12 \mathrm{~h}$ after inoculation and germination reached $95-99 \%$ by $48 \mathrm{~h}$. No differences in germination, germ-tube production and stomatal penetration between the abaxial and adaxial leaf surfaces were observed in the present experiments and this supports the report of Cook (1981) that the leaf surfaces did not differ in susceptibility to $P$. personata. We did not observe penetration through lateral faces of epidermal cells as reported by Jenkins (1938).

It is not clear what causes tropic growth of germ tubes and germ-tube branches towards stomata with intermittent wetness, but it is possible that the pathogen detects gradients of either humidity, $\left[\mathrm{O}_{2}\right]$ or $\left[\mathrm{CO}_{2}\right]$ from stomatal pores or some other chemical stimulant when the leaf surface is dry. Oxygen concentration has been shown to affect branching in Polyporus arcularius (Valla, 1984) and carbon dioxide concentration is known to affect autotropism in Botrytis (Jaffe, 1966). In an additional experiment we incubated inoculated plants with intermittent wetness and compared light and dark conditions during the dry periods. Similar germ-tube growth patterns and lesion numbers were observed in both treatments, suggesting that the pathogen was not responding to $\left[\mathrm{CO}_{2}\right]$ or $\left[\mathrm{O}_{2}\right]$ gradients. In vitro, we observed few branches with intermittent wetness, so it appears that branching is associated with conditions on the leaf surface. On leaves, no directional growth of germ tubes was observed with continuous wetness and it appeared that the few stomatal penetrations by germ tubes occurred by chance when germ tubes happened to reach stomata. These observations agree with other results reported for detached leaves incubated in saturated conditions for long periods (Abdou $e t$ al., 1974; Cook, 1981). The possibility of a hydrotropic response by germ tubes was suggested earlier for $P$. personata (Cook, 1981) and this seems feasible from our circumstantial evidence. Rathaiah (1976) also suggested that enhanced penetration by Cercospora beticola with interrupted wetting may be owing to hydrotropism.

Germ-tube branches, induced by interruptions in leaf wetness, were particularly important because they exhibited strong tropism towards stomata followed by penetration (Fig. 3a). 


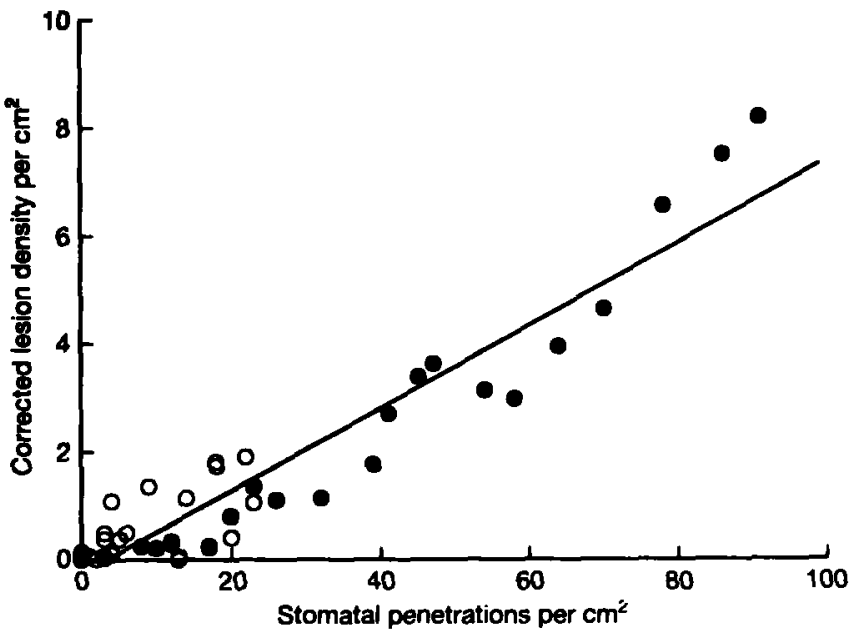

F5. 4. The relationship between the number of stomatal penetrations by germ tubes and germ-tube branches of Phaeoisariopsis personata on groundnut leaves and the number of resultant lesions. The inoculum density was about 60 conidia $/ \mathrm{cm}^{2}$ (sum of both leaf surfaces) and observed lesion density was corrected for multiple infections. $\bullet$. intermittent wetness; 0 , continuous wetness.

Production of short branches from germ tubes in close proximity to stomata was absent with continuous wetness (Fig. 3b). There is a good linear relationship between the number of germtube branches and stomatal penetrations (Fig. 6a), but more scatter when only germ tubes are considered (Fig. 6b). Furthermore, about $60 \%$ of the branches penetrated stomata (Fig. 6a), but the proportion of germ tubes that penetrated stomata was much less (Fig. 6b). Alderman and Beute (1986) observed that 6 days after inoculation with $C$. arachidicola, an increase in the number of germ tubes did not result in a corresponding increase in the stomatal pene-

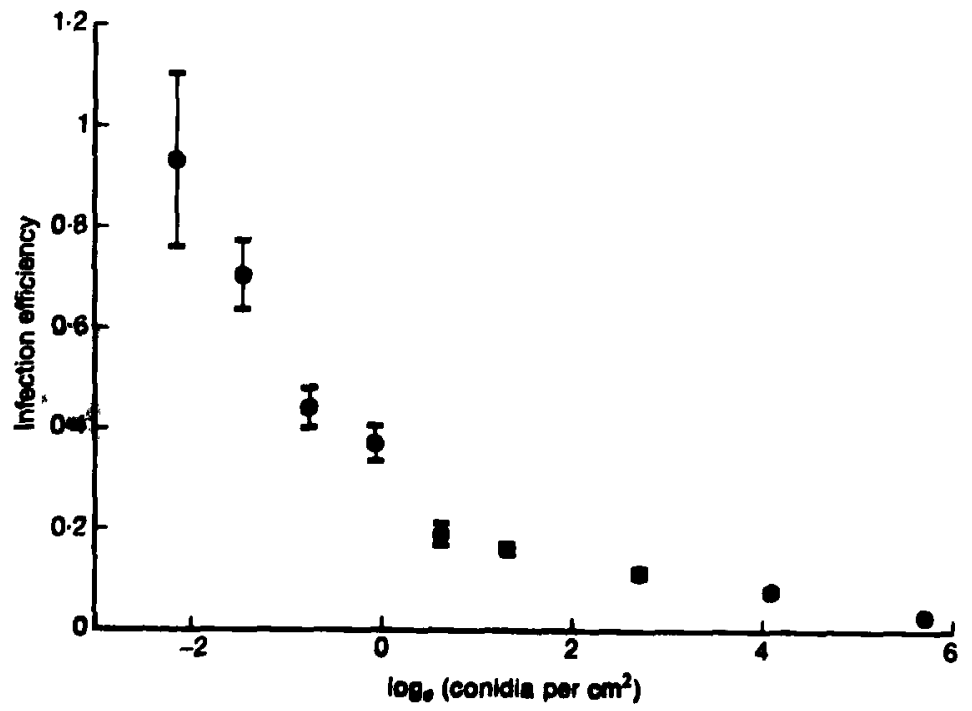

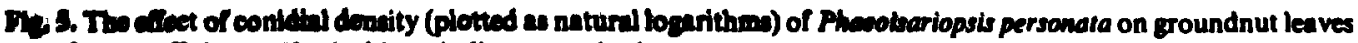
on bertion efleiency. Vertical barn indicate standand errors. 
Table 3. Mean numbers (with standard errors) of germ tubes and germ-tube branches from germinated conidia of Phaeoisariopsis personata with wet/dry cycles (in vitro). Each cycle is $24 \mathrm{~h}$ wet followed by $24 \mathrm{~h}$ dry and $24 \mathrm{~h}$ wet.

\begin{tabular}{ccc}
\hline No. of cycles & Germ tubes/conidium & Branches/conidium \\
\hline 1 & $4.9 \pm 0.3$ & 0.0 \\
2 & $6.4 \pm 0.3$ & $0.8 \pm 0.2$ \\
3 & $8.5 \pm 0.5$ & $1.2 \pm 0.2$ \\
\hline
\end{tabular}

trations. Reduced penetration of host tissue under continuous wetting regimes has also been observed with C. musae (Goos \& Tschirch, 1963), C. beticola (Rathaiah, 1976) and Cercospora zeae-maydis (Beckman \& Payne, 1982).

The fact that stomatal penetrations increased linearly with intermittent wetness up to an accumulated wetness duration of $88 \mathrm{~h}$ (about 6 days after inoculation) indicates that $P$. personata is slow growing prior to penetration, and is well adapted to tropical environments where evaporation rates are rapid and leaves dry quickly after rain or dew. Although lesion number was linearly related to the number of stomatal penetrations, the number of penetrations was always much greater than the lesion number. This corresponds to observations by Cook (1981) and Rathaiah (1976) for $P$. personata and $C$. beticola, respectively.
In vitro tests to determine survival of germinated conidia to interrupted wetness cycles indicated rapid recovery of dried conidia and germ tubes to rehydration. Germ-tube growth continued and initial dry cycles promoted germtube production from additional cells of the conidia. This indicates that the pathogen not only survives dry periods after germination of conidia but is stimulated by them. Similar stimulation has been observed with other pathogens, e.g. interrupted wetness promoted germ-tube growth, branching and production of germ tubes from more conidial cells of Wilsonomyces carpophilus on almond leaves (Shaw et al., 1990).

It has been demonstrated in this study that multiple penetrations from each conidium with intermittent wetness, accounted for the observed increase in infection efficiency compared with
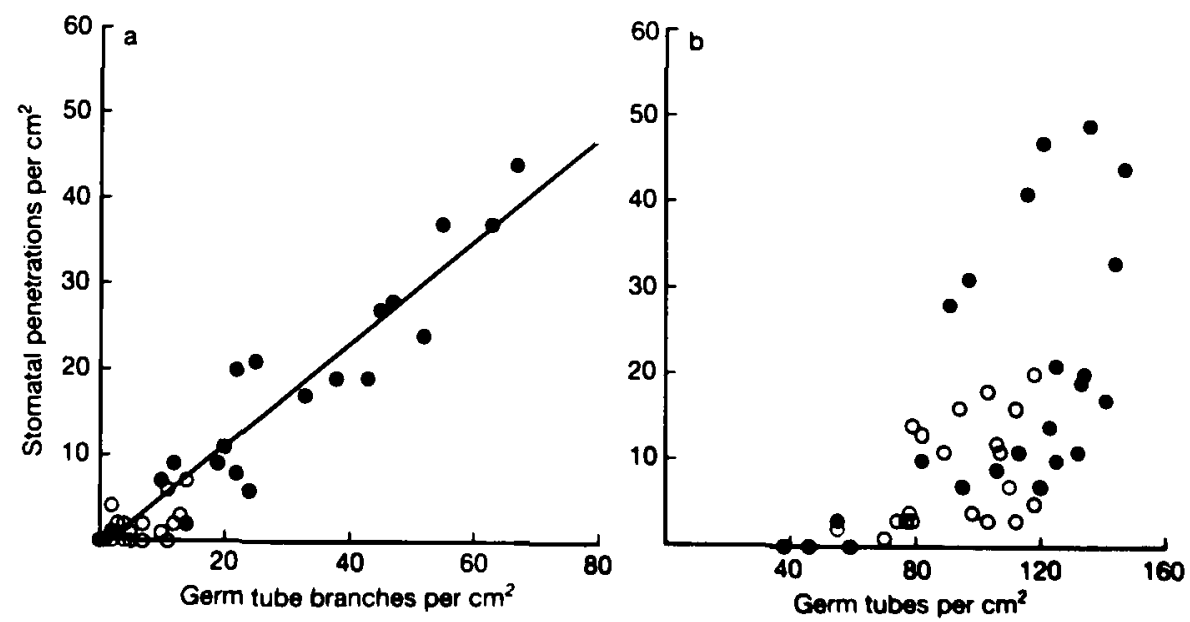

Fig. 6. Relationships between (a) the number of stomatal penetrations by germ-tube branches of Phoeoisariopsis personata and number of germ-tube branches observed on the surface of groundnut leaves, and (b) the number of stomatal penetrations by germ tubes and the observed number of germ tubes. The inoculum density was about 60 conidia $/ \mathrm{cm}^{-2}$ (sum of both leaf surfaces). The regression in $(a)$ is given by: $y=0.601 \times-1.494(r=0.92)$. intermittent wetness; $O$, continuous wetness 
continuous wetness. Infection efficiency also varied with spore load. At the greatest concentration of conidia ( 300 spores $/ \mathrm{cm}^{2}$ ) we found that one lesion corresponded to about 33 conidia. A comparable result was obtained by Nevill (1981) with $P$. personata on TMV 2 , which he expressed as percentage spore success. Nevill inoculated only the adaxial leaf surface, and used an inoculum concentration of 100000 conidia $/ \mathrm{cm}^{3}$ which is equivalent to 50000 conidia $/ \mathrm{cm}^{3}$ in our experiments, where we inoculated both surfaces. We used a similar application technique to Nevill, therefore it is reasonable to assume similar retention of conidial suspension. With this assumption, 100000 conidia/ $/ \mathrm{cm}^{3}$ would give about 300 conidia $/ \mathrm{cm}^{2}$ on one side of the leaf, for which the spore success was $2.2 \%$ (one lesion from 45 conidia). Nevill (1981) suggested that there may be interference between conidia or competition between infection sites at high inoculum concentrations. Before lesions became apparent, we observed incipient lesions within the leaf tissue when held against bright light. With 600 conidia $/ \mathrm{cm}^{2}$ leaf area, about 50 incipient lesions $/ \mathrm{cm}^{2}$ were counted, which gave rise to about 20 lesions $/ \mathrm{cm}^{2}$ at the time of lesion appearance. This suggests that over half of the incipient lesions were being suppressed prior to lesion appearance. However, the effect is much less at lower conidial densities. Furthermore, in Fig. 5 we examined a much wider range of conidial densities than Nevill and the largest change in infection efficiency occurred at smaller conidial densities when infection sites would not be limiting. Indeed, there appeared to be strong interference between conidia even when the number of conidia changed from one to two conidia per leaflet. With densities of less than one conidium $/ \mathrm{cm}^{2}$ it is unlikely that this interference would be direct and it is possible that it is mediated through physiological changes in the host.

As maximum infection efficiency occurs with minimum spore load and intermittent wetness, it appears that a single conidium has high chance of causing a lesion (Fig. 5). This is important early in the crop season when the disease is first established in the field and initial infection depends on very few conidia. Earlier reports (e.g. Nevill, 1981) indicated low infection efficiency for $\boldsymbol{P}$. personata, but our results suggest very high efficiency (approaching one lesion per conidium) with intermittent leaf wetness and extremely small conidial density.

\section{ACKNOWLEDGEMENTS}

This paper is journal article no. 1563 of the International Crops Research Institute for the Semi-Arid Tropics (ICRISAT).

\section{REFERENCES}

Abdou YA-M, Gregory WC, Cooper WE, 1974. Sources and nature of resistance to Cercospora arachidicola Hori and Cercosporidium personatum (Beck \& Curtis) Deighton in Arachis species. Peanut Science 1, 6-11.

Alderman SC, Beute MK, 1986. Influence of temperature and moisture on germination and germ tube elongation of Cercospora arachidicola. Phytopathology 76, 715-9.

Bashi E, Rotem J, 1974. Adaptation of four pathogens to semi-arid habitats as conditioned by penetration rate and germinating spore survival. Phytopathology 64, 1035-9.

Beckman PM, Payne GA, 1982. External growth, penetration, and development of Cercospora zeaemaydis in corn leaves. Phytopathology 72, 810-5.

Broughton WJ, Dilworth MJ, 1971. Control of leghaemoglobin synthesis in snake beans. Biochemistry Journal 25, 1075-80.

Butler DR, 1990. Weather requirements for infection by late leaf spot in groundnut. In: Hildebrand GL, Schmidt G, Singh L, Subrahmanyam P, Wightman JA, eds. Proceedings of the Fourth Regional Groundnut Workshop for Southern Africa 19-23 March 1990. Patancheru, India: ICRISAT, 99-104.

Butler DR, Wadia KDR, Jadhav DR, 1994. Effects of leaf wetness and temperature on late leaf spot infection of groundnut. Plant Pathology 43, 112-20.

Carisse O, Kushalappa AC, 1992. Influence of interrupted wet periods, relative humidity, and temperature on infection of carrots by Cercospora carotae. Phytopathology 82, 602-6.

Cook M, 1981. Susceptibility of peanut leaves to Cercosporidium personatum. Phytopathology 71, 787-91.

Gäumann E, 1950. Principles of Plant Infection. (Brierley WB, English editor). London, UK: Crosby Lockwood \& Son.

Good HM, Zathureczky PGM, 1967. Effects of drying on the viability of germinated spores of Botrytis cinerea, Cercospora musae, and Monilinia fructicola. Phytopathology 57, 719-22.

Goos RD. Tschirch M, 1963. Greenhouse studies on the Cercospora leaf spot of banana. Transactions of the British Mycological Society 46, 321-30.

Gregory PH, 1948. The multiple-infection transformation. Annals of Applied Biology 35, 412-7.

Jaffe LF, 1966. On autotropism in Botrytis: measurement technique and control by $\mathrm{CO}_{2}$. Plant Physiology 41, 303-6.

Jenkins WA, 1938. Two fungi causing leaf spot of peanut. Journal of Agricultural Research 56, 317-32. Lannou C. Blizoua Bj P. 1989. Conditions for the 
development of $C$. personatum leaf lesions on groundnut after artifical infection. Oléagineux 44, 531-5.

Nevill DJ, 1981. Components of resistance to Cercospora arachidicola and Cercosporidium personatum in groundnuts. Annals of Applied Biology 99, 77-86.

Rathaiah Y, 1976. Infection of sugarbeet by Cercospora beticola in relation to stomatal condition. Phytopathology 66, 737-40.

Schein RD, 1964. Design, performance and use of a quantitative inoculator. Phytopathology 54, 509-13.

Shaw DA, Adaskaveg JE, Ogawa JM, 1990. Influence of wetness period and temperature on infection and development of shot-hole disease of almond caused by Wilsonomyces carpophilus. Phytopathology 80, 749-56.
Shaw MW, 1991. Interacting effects of interrupted humid periods and light on infection of wheat leaves by Mycosphaerella graminicola (Septoria tritici). Plant Pathology 40, 595-607.

Shew BB, Beute MK, Wynne JC, 1988. Efiects of temperature and relative humidity on expression of resistance to Cercosporidium personatum in peanut. Phytopathology 78, 493-8.

Valla G, 1984. Hyphal extension and branch initiation in Polyporus arcularius: a biolaser microsurgical investigation. Canadian Journal of Botany $\mathbf{2}$, $2788-92$.

Wadia KDR, Butler DR, 1994. Relationships between temperature and latent periods of rust and leaf spot diseases of groundnut. Plant Pathology 43, 121-9. 
This document is a scanned copy of a printed document. No warranty is given about the accuracy of the copy. Users should refer to the original published version of the material. 